fications of the forces which act upon it. The desired unity, then, was far from being realised before the appearance of that repulsive force acting at a distance which the cometary phenomena definitely inscribe in the mechanism of the heavens by the side of attraction, and which I find around us in the phenomena of heat.

At all events, we have got a great way from that judicial astrology which I felt bound to remind you of at the outset, in order to show to you the condition in which we found that branch of celestial science. While, in planetary astronomy, scarcely anything has been done for two hundred years but to develop indefinitely the mathematical formulze of a force established and defined, we have tried here to put ourselves on the track of a force which rules more especially the cometary world, and have endeavoured to give it a name.

\section{THE AMERICAN OYSTER-TRADE}

GOME notion of the extent of the trade in oysters at Baltimore may be gathered from a recent report of the British Consui. Baltimore, it is said, is recogrised all the world over as the great centre for raw oystersNew York as well as the Southern and Western States depending on it for their supplies. The packing-houses in Baltimore have agencies in all the large cities and towns, and these agencies have sub-agencies covering the country districts. About twenty firms are engaged in the packing and distribution throughout the States of raw oysters, 5,000,000 bushels of which are annually consumed to meet the demands of the trade, which is one not only incurring great risks, but also requiring some tact for its successful management. Such is the perishable nature of the oyster that the risk in handling them has much to do in determining their price. Delays in the arrival of a vessel will often cause a whole cargo to become putrid, so that it has at once to be thrown overboard. To cover these risks the margin of profit is necessarily large. Large numbers of men, women, and children are employed in opening the oysters and removing them from their shells: for this work they receive 20 cents per gallon, and the average earnings of each person are about two dollars per day of ten hours.

In packing the raw oysters they are, after being opened, washed carefully, then placed in flat cans with a little fresh water, as the liquor or natural juice of the oyster decomposes in twenty-four hours after exposure. These cans are then packed in rows with cakes of ice between them, and shipped by express to their destination. At certain points it is arranged that these cases destined for the far west shall be opened, fresh ice placed between the cans, and then re-shipped to their ultimate destination. Oysters packed in this way and re-iced at certain places on the route can be sent from. Baltimore to San Francisco in good condition. Besides this trade in raw oysters as many as 3,000,000 bushels are annually steamed and hermetically sealed in tins for shipment to all parts of North America and to Europe. The season lasts from Oct. I to April I. By the steaming process the oysters are so preserved that after being sealed down they will keep good for an indefinite period of time.

\section{RUDE STONE MONUMENTS OR CHAMBERED BARROWS}

\section{I.}

THE object of the present and succeeding articles is to discuss some of the opinions which are held by some of the leading antiquaries of the present day with respect to the construction, destination, and also antiquity of these monuments, and to show that, notwithstanding all the advantages presented by the establishment everywhere of Archæological Societies, the publica- tion of their journals, and the increased facilities for travelling, many professed students of this branch of science are still found to be blindly adhering to the views of antiquaries of the past century. There is a very remarkable contrast between the progress made in the study of unchambered, and in that of chambered, barrows. We have now a much sounder knowledge of the former than of the latter, not simply because the latter are more difficult to understand, but because their study requires qualifications not possessed by every investigator. He must have long acquaintance with the monuments, sufficient dexterity in drawing and surveying to make accurate plans, sections, and elevations, be a close and unbiassed observer, and then have leisure to devote his intelligence to the scrutiny. Cursory examination will be always fatal to the acquisition of sound knowledge, and serve to mislead others; and it is greatly to be feared that this has been too common a habit and result.

The first erroneous opinion to which attention is now directed is that very many of the cromlechs or dolmens (to employ terms which are in general use), i.e. rude store structures which in the British Islands and on the Continent are partially or wholly exposed to view, were never in any other condition; that is to say, that although they may be in some measure dilapidated now, yet that they were originally intended to be exposed buildings. They are aware that many other structures of analogous forms are imbedded or enveloped in mounds so as to be invisible externally, but they will not allow that the exposed ones ever were so. As long as these authors confine themselves to the bare declaration of their belief their position is not so assailable; but when they point to the monuments which they say illustrate their arguments the case is altered. The examples are open to the inspection and consideration of everybody, and the accuracy of their descriptions can be tested. This has been done, and the result has been that numberless inaccuracies have been detected in the published accounts and in the plans; and the conclusions which have been deduced from them are consequently pronounced to be erroneous.

It will be sufficient to point out this in a few of the well-known monuments to which they have directed our attention; and as no author has treated the subject so comprehensively as $\mathrm{Mr}$. Fergusson, or been so methodical in the arrangement and classification of the monuments, his recent work* will be particularly referred to in the following pages. He has admitted that he is indebted for much of his information to the published accounts of others. It must be premised that we do not assert there is positive proof of the former cxistence of the mounds, nor do we say that there is any tradition of them, but we say that when the exposed monuments are compared with those which are wholly enveloped, and with those numberless instances in which the traces, in many examples very extensive traces, of the mounds still exist, the fair and legitimate inference is that these so-called "free-standing" structures $\dagger$ were once monuments of the same class as the others, and that they are only in a more advanced stage of decay at the present time.

We go a step further, and say that there are so very fer instances in which no trace whatever of a mound remains that the argument from inference is greatly strengthened. Have the advocates of the theory ever attempted to sum up carefully all the examples of total denudation? It has been remarked by the author of "Rude Stone Monuments in all Countries," p. 44, that "probably at least one hundred dolmens in these islands could be enumerated which have not now a trace of any such envelope." There is a confidence in this statement which invites scrutiny, and we venture to say at the outset that it is far from being accurate, for we know that

" "Rude Stone Monuments in all Countries, their Ages and Uses." $\dagger$ These are defined to be dolmens which were never intended to be hidder in any earthen covering, and about which no trace of 2 mound exists. 